\title{
PROGRESS DEPENDS ON UNBALANCE AND DISORDER
}

\author{
A. Can ÖZCAN, BID,MSc,PhD. \\ Assistant Professor \\ İzmir Institute of Technology \\ İzmir, Turkey
}

\begin{abstract}
Walking is a state of unbalanced body. Not to fall down, it takes a way. Technology is another state of progress depending unbalanced structures of human functions and relations. In balanced societies and cultures which are being considered as technologically primitive, what we see is lack of technology, but a state of balance and order. It is not surprising to see that great technological developments have appeared under most unstable conditions. Especially in the Industrial Period the Western culture has witnessed enormous unstabilities in social, cultural, ethical, logical, and aesthetic structures. During the period of "the immense technological alterations" world has experienced two large scaled wars with countless small scaled ones, large scaled hunger, and large scaled and ever increasing contradictions between parties with social and mental extremities from religious extremities to drug addiction and high depression. Hand in hand with these developing contradictions and extremities there seems to be another development which appears in technological area that makes us ask the question if there is a relation among these.
\end{abstract}

Technology was once the vital element of mankind to survive in nature for he was equipped with the weakest properties. But today, technology has reached a perfection level above any natural entity including homo technologicus. And thus, the natural selection has become the technological selection. Once a servant for mankind, has become the master. Genetical reproduction is nothing but a manifest that only the ones selected by technology are going to survive. You can never find a naturally grown entitiy in human environment apart from the selected and artificially planted ones. Whole nature is nothing but a zoo for next generations.

I as a member of an institution of technology and working hard to develop it am not suggesting an impossible turning back (to what?) or stopping everything. What I am suggesting is to "repair" our mental attitudes towards life with no threat on the others. If our attitude towards life does not depend on ethical, logical, or aesthetic principles we will only have a high technology selecting rich, wealthy, powerful and discriminating the rest including the nature itself. 
Walking is a state of progress depending on unbalanced and disordered bodies even in the most physical and natural sense. The body takes a way not to fall down. If we take technology as a progressive attitude of human abstraction we can not escape the dark side of our abstraction ability especially in disordered conditions, and we can not deny the fact that technological developments have always been motivated by unbalanced social, natural, and constitutional conditions throughout history. In stable societies which are being titled as technologically, and also socially primitive, the balance and the lack of change provide a sense of security in every manner. We do not see a progressive technology, but a balance and order in such societies, which represent the opposite condition of our modern societies which are technologically progressive with unbalanced and disordered conditions in a lack of security.

It is not surprising to see that great technological developments have always appeared under most unstable conditions. Stone age implements were created to survive against wild nature, military wonders of technology have always been developed to conquer or beat the others from Alexander The Great to the Gulf War. Especially in the Industrial Period the Western culture has witnessed enormous unstabilities in social, cultural, ethical, logical, and aesthetic structures. And during this period of "the immense technological alterations" world has experienced two large scaled wars with countless small scaled ones, large scaled hunger, and large scaled and ever increasing contradictions between parties with social and mental extremities from religious extremities to drug addiction and high depression. Today there exist global tensions between East and West, North and South, natural and artifical, rich and poor, not skipping this religion and that religion. Hand in hand with these developing contradictions and extremities there seems to be another development which appears in technological area that makes us ask the question if there is a relation among these. People are commuting suicides in masses with NIKE footwear and leaving messages on web pages that they were on their way to a UFO coming after the Hale-Bopp comet. Every minute a natural living creature is being subject to extinction because of our "abstracted" attitude towards life, and the same abstraction ability is being extensively used to create genetically reproduced copies of species. I think these pictures are clear enough to reflect our mental attitude towards life with high technology. Don't blame poor and underdeveloped countries because of the population explotion. It is only a natural response to "survive" against developing contradictions. In U.S.A., annual expense for diet and to reduce calory consumption ssems to be around 5 or 6 billion dollars. And while Americans are getting fatter and fatter with the most primitive menu in the human culture, half a billion people are starving to death or suffering mental or physical injuries because of insufficient nourishment. I think those fat people should thank the overpopulation on the world which keep them spending more for diet. We can convert this fact into scientific measures too. Today, $80 \%$ of the whole world population live in the countries and regions which are considered to be poor. Industrialized countries of the world is only $22 \%$. This $22 \%$ consumes $60 \%$ of the food, $70 \%$ of the whole energy, $75 \%$ of the whole metal, and $85 \%$ of the whole wood. To tell the poor not to give birth more, will only increase the share of $22 \%$ in consumption and their expenses to get thinner. Giving 
birth is the inevitable end product of the "call of nature" and latest developments have proved the fact that agricultural resources of the world will be more than enough even for more than billions and billions of people. So population is much more a matter of quality, than a matter of quantity (and it reminds me of Hitler racism in disguise). "If you are poor, crowded and technologically underdeveloped, then die. Because I will never use my wealth and technology to solve your problem, rather I will see you as a problem for me to get wealthier, and technologically much more developed.." Though we are accustomed to see overpopulation as a reason for poverty, the fact is actually the reverse of what is in our minds. That is to say poverty is the reason for overpopulation, and if we start to examine poverty there we meet with our approach towards using technology.

On the other hand, to the gigantic number of people starving in the $78 \%$ of the planet earth there seems to be gigantic number of spiritually starving people are being added from the $22 \%$. Remember mass suicides, drug addiction, distorted sex habits, over depression, etc., etc.,

And our technology has nothing to do with solving the problems I've mentioned. You may say these are nothing to do with technology, but you may probably be wrong. Of course, I am not blaming technology for it is neither bad nor destructive. It is our attitude to blame for using technology for our bad and destructive purposes. And the keyword to the use of technology is of course "politics". We ususally believe or want to believe that technology is neutral and technological developments belongs to the whole mankind. If somebody named Armstrong puts his feet on the moon we want every living human being from east to west of the world and from the north pole to south pole to be proud. If somebody somewhere reproduces a sheep genetically we want everybody on this planet to share the feeling "wow". Please tell me how many of the world population really mind landing on the moon, or the star wars project, or cyborgs, or semi-conductor technologies, or reproducing a sheep, or travelling on and in different types of levers, or developing new technlogies that can extriminate the whole mankind not once, but several times. Who cares about the new power engine unless you promote it as the latest development in technology but never seem to let me produce or even use it. Yes you may want me to consume it if I pay the bill of course.Technology is not neutral, and never will be. It is and will always be, on the side of the politics those motivate and create technology, and use it for the sake of that politics in return.

Everybody involved in here knows that the primary function of technology is to solve problems., and I counted a few basic ones. A simple stone axe was solving the problem of survival for the whole mankind. But today one bottle of poisoned gas is a threat for a whole city and highly developed technological military power is a threat for all of us. As Victor Papanek puts it well, today the number of people living in the dark are much more than the times Edison invented the light bulb. We all may be amazed by the latest technology in light bulb filament and impressed by the "quantitative" parameters but it will never change the fact that tomorrow there will be much more people in the dark than today, till only the ones in the light will be selected one way or another.

As long as we all know mankind is really a special kind among all the living creatures on the planet earth regardless of the rest of the universe. And 
the main task which differs us from the rest of the nature is our "abstraction" ability. We seem to be the only living creature whose interrelation with the environment occurs through abstracted processes. Even from the point of basic biological functions, man behaves through abstractions. Take our basic sheltering or feeding habits. We abstract these functions totally different from the rest of the natural living creatures. And nature has always created a balance among its elements. Sharks or lions attack regardless of any abstraction or thought to feed themselves. Natural instincts and motivations combined with the natual capabilities form an ordered balance among living species. A shark lives with an unsatisfacion of food. And they can only survive through a never ending search for food. The nature lets them find only enough food to live in balance with the other living creatures. In nature it secms or it once seemed that everything existed on a well calculated scale and order. I've discovered that If I feed my fishes in the aquarium with more food than they need, they don't stop when they are satisfied and continue eating till they die. The same instincts and motivations can be observed in all living creatures. They live with basic calls of nature: "you are hungry, go eat that rabbit; or you are sleepy, lie down and sleep and they never abstract their ways of life like humans do. What I call abstraction is what our living habits are. We do not eat or perform reproduction habits according to the call of nature. We perform living and survival with very specific abstractions belonging to everything around and within. And only through this abstraction ability, human kind have managed to survive among competing species, where most of the others were naturally better equipped. His abstraction ability has changed the course, balance and the order of nature with no turning back. Without abstracting the physical environment he was living in, his natural capacity was not enough to keep him alive. He could not run, fly, swim, or fight better than the competing species for natural selection. But the moment he had abstracted a piece of rock as a weapon that can save his kind's life, has changed his grade in nature and started technological abstraction against all the others lacking this ability.

From this point of view we can easily state that man has never been a part of the nature, but always has existed by abstracting it through four basic abstractions: logical, ethical, and aesthetical abstractions on one side, and technological abstraction on the other. The supreme abstraction that converts nature into what we call science and technology has been the masterpiece of man's abstraction ability among the others. When I say man has never been a part of nature I mean it. Because nature has limits and an order without a causc. But man's abstraction ability knows no limits and always tends to put its conclusions on a reasonable abstraction. Take mathematics for example. It is a perfect example of abstraction expressing every factual thing on an abstracted basis with no limits. Every schoolboy knows the dilemma that you can never cover a distance if you depend on mathematics (because of the simple mathematical principle that between every mathematical point there exist infinite number of points. That is to say, you can spend all your time by counting from 1 to 2 , but you can never reach 2). Oppositely, if you don't count on mathematics you can never build spacecrafts, or computers. But the main fact stays as it is. What we call mathematics is a function of human abstraction but not a function of nature. Maybe that's why Kant 
has said something like "two plus two makes 4 on this earth, but I am not sure what it makes on other parts of the universe".

Seeing a piece of rock and abstracting it as a technological device for survival is one thing, what we call technology today is some other thing. But both depends on our limitless, scaleless, endless abstraction ability in a limited and scaled nature with a physical end of everything. End of resources, end of living species, end of waters, end of lives. Technological abstraction knows no limits but physical nature can not function without limits. That's why man has always tried to eternalize his nature through his abstraction ability, through art, through technology, through whatever his abstraction capacity leads him. If human abstraction ability towards nature is titled as science, technology, art, his abstraction towards his own existence is called as that keyword I've mentioned before "politics", and these categories are never external to each other but rather internally combined within. By the way, nature which is limited and scaled in a stable order knows of no politics except the only development that we call evolution, the selection of suitable and improvement of necessary. Today's industrial capitalized system depending on technology and politics copy this selection method of nature in a way, but while doing this uses only quantitative and economical criteria. It is an interesting observation we can make that we've replaced most of qualitative factors (which usually depend on ethical "good", logical "right", and aesthetical "beautiful") with quantitative terms. A computer on my desk is good if its RAMs ROMs or HDD capacities are bigger in quantity. It does not matter if the factor depends on an increase or decrease. For example today a good car depends on another quantitave factor which is "less" fuel consumption (twenty years ago it was "more" speed). The important thing is the use of quantity in expressing quality. I know that quantity is the chemistry of engineering and technology, but it makes no sense without a philosophy of living, and I can easily say that we are about to lose four basic existence levels in favour of a high technology which is definitely much more better than any human being in quantitative terms, and a wild and competitive political economy that the majority of the globe is suffering from. What I mean with four basic human existence levels are natural, logical, ethical, and aesthetical existence levels and all our spiritual, or you may prefer to use psychological, or even medical sufferings derive from the lack of these four existencial supports.

To get a clearer picture of what I mean let's take a look at these four human existence levels with respect to technology.

Because of technological abstractian and creativity we lost all our sense of nature and I can assure you that we all are just like the last of the Mohicans when compared with tomorrows' environment and forthcoming generations. Most of us have had the chance to experience a natural contact with the environment. For example we all saw naturally grown trees or ate natural fishes from seas which are not polluted yet. We saw naturally running rivers with no control over their existence. We saw landscapes or jungles where animals and plants lived just because they have existed naturally for the sake of their own existence. But today the world is living the biggest transformation stage since it has appeared in the universe and it is a transition from a natural existence to a human controlled existence. Today you 
can never see a naturally planted tree in our living environments. Any plant or any flower is there just because it is a part of a human plan or design. The whole world is turning out to be a big zoo to satisfy our natural side, ease our shame and dry our alligator tears against masses of naturally born plants and animals but subject to human violence. Today most of the species are subject to extinction just because they are not economical, or useful, or connected to human existence in some way. Thorstein Veblen has named this phase as "predatory phase" about a hundred years ago. Now take a look at our children. The term nature means a terrible and usually a wild and horrible vacation for them, if it is not so for us. They are much more satisfied while sitting in front of a TV set or a computer screen rather than climbing a tree. I am sure that a tree or an animal will mean nothing to the next generations unless they have a quantitative value or a use for they've never experienced a relationship. I am sure that our children will stop considering themselves as a part of nature. Look at our cities. I have no feeling of a natural environment apart from a very useful design for my living. I am a professional industrial designer enough to know that every design reflect human intention, and all the technological devices around me reflect no intention towards the nature that we were once a part of. Take a look at the design of our appartments, cars, everyday gadgets. They reflect no sense of nature but a bunch of totally different concepts which are all human abstractions in origin. Sure nature is still involved in our way of living. It is a big market to make profit and if it is not, it is something "wild" or "dangerous". We have thousands of designs to protect us from nature. We have glasses to protect us from the sun, or different types of coatings to protect us from the weather after millions of years. If our environment is somehing to be protected from, then just get rid of it, and this is our intention nowadays. And we have all the technology in hand to get the fiction to a fact. I'd like to believe that the future we are creating will be sterilized from the problems we are suffering today, and we will be happier and healthier in an environment with nothing to do in todays' sense. But all $I$ feel is that the selected ones will only be wealthier for we are also loosing our logical, ethical, and aesthetical abstractions.

The basic principle for logical abstraction lies in the terms "right" and "wrong". If we do not have a sense of what is right and what is wrong then it means that we've lost our logical abstraction ability. You can not replace the qualitative answer for right and wrong with quantitative factors. Logical human existence can not get satisfied with quantitative answers. There is a difference between the right angle and the logical abstraction. We must have a logical abstracion for our technology. We must ask ourselves if it is right to depend on nuclear energy, and must find an answer apart from quantitative reasoning. We need logical answer for questions like "is it right that the technology I create can make a majority suffer in favour of a minority's wealth?" or "is it right that the technology I am creating is making a lot of human being useless, or just giving them a sense of uselessness? (Don't tell me that old lie that because of improved technology we will be doing what we really want -art for example-, but not work. Tell me what if all we want and need is work for our a healthier personal and social existence), or, "is it right that I lost all my communication with my neighbour but I can communicate with the other side of the world through my computer?", or "is it right that 
while my kitchen is getting technologically well equipped my food is getting tasteless, and I am getting fatter?"

Though it may be possible to find not that logical but "reasonable" (because reasoning is another abstraction) answers for our "right or wrong" questions, the lack of ethical side in our existence is clear. For the basic principles lie in "good" and "bad" for ethical existence, we usually avoid asking ethical questions in science and technology. Though the whole principles of science and technology are functions of human mind and its abstractions, we find ethics "too abstract" for science and technology . We seem to prefer working on science and technology for the sake of science and technology's own sake and never asking questions "good" and "bad". Of course there comes a time for all of us to ask ethical questions and it usually happens when the going gets tough. When somebody reproduces a sheep genetically, or when we start watching a war just like a computer software, or when we see our children getting more violent in front of actual or fictional terror we start asking ethical questions.

From the point of aesthetics, science and technology seems to be taking the opposite direction of what it does with logic and ethics. Today not only scientific and technological era but every human creation seem to reflect the basic principle "beautiful". Even the terrible news are being broadcasted with a special emphasis on aesthetics. Most of all remember the dying bird in fuel scenes during gulf-war but isn't it strange that we didn't see any dead bodies. There is a strange combination of aesthetics with other human abstractions nowadays. The music videos seem to depend on disgusting scenes and the screensavers on computers are usually different types of cockroaches or unusual creepy creatures. We seem to enjoy disaster movies more than ever and have fun when explosions, crashes, and violence gets aesthetically handled. Don't we still see that our abstractions reflect our intentions, and what we intend to do with the science and technology at hand is only speeding our movement towards our intentions with no sense of aesthetics, ethics, and logic.

By the way, we don't seem to be organizing symposiums or conferences when things seem to be going O.K. Usually if there are a lot of symposiums or congresses, or conferences on a certain subject there usually exist problems. Take AIDS or Blod Pressure meetings in medicine, take large scaled Habitats, or take Technology and Symposium meetings. These do all obey the rule that we come together if problems arise. (Do you remember any symposium on Color of Black People?).

I will conclude by mentioning a sharp edge that, until finding scientific or technological solutions for our problems (usually creations of our scientific and technological and socio-economical politics), we can solve most of them by changing our mental attitude towards human existence. We created a culture that conquered the nature on earth and ready to conquer the space now. But we are still suffering from very shameful attitudes towards life and to our own kind for we lost idealistic principles of "good", "right", and "beautiful". Existing and available technolgies seem to be enough to solve most of the problems of the whole worlds' inhabitans. But if the question is not to use technology to solve problems on earth but to satisfy a minority's fiction about human life through politics with no sense of logical, ethical, and aesthetical abstraction, then get ready for the contradictions and the extremities go further and 
never ask the question "what was wrong with it" after it is too late.

I, as a member of an institution of technology and working out to develop it, am not suggesting a turning back to natural roots (which is totally unnatural for human kind) or advocating a mystical metaphysics (that's why religions are getting stronger nowadays) or a kind of anarchism. I am spending most of my time to be selected in tomorrows' world which depends on violent competition to produce science, and technology. Without employing and reproducing know-how I know that I won't be a part of the world I am living in. Rather I will be added to the chain of species and cultures discriminated. But why not create a better world with our technology just by "repairing" the disordered attitude of our abstaction for it has lost the sense of balance, ethics, logic, and beauty.

I lost my balance but I learned to walk that can take me somewhere if I can manage to define it. Otherwise I will only appreciate my speed which will take me further and further till I get lost in every sense. I am suggesting a definition of future with a respect to life and no threat to any living thing.

\section{REFERENCES}

1- K. Hoffman, "Technological Change in

Telecommunications; Implications for Industrial Policy in Developing Countries", New Technologies and Global Industrialization Prospects for Developing Countries, PPD, 142, 13 November, 1989 2- Ivan Illich, Tools for Conviviality, England, Fontana/Collins, 1975

3- Victor Papanek, Design For The Real World, New York, Granada Publ., 1974

4- $\quad$ Robert M. Pirsig, Zen and The Art of Motorcycle

Maintenance, An Inquiry into Values, Vintage, 1989

5- E.F. Schumacher, Small is Beautiful, London, Abacus Books, 1973

6- $\quad$ Edward J. SylvesterKynn C. Klotz, The Gene Age, New York Charles Schribner's Sons, 1983

7- $\quad$ Thorstein Veblen, The Theory of The Leisure Class, Allen\&Unwin, 1971

8- $\quad$ Yevgeny Yevtushenko, A Precocious Autobiography, New York, Dutton, 1963

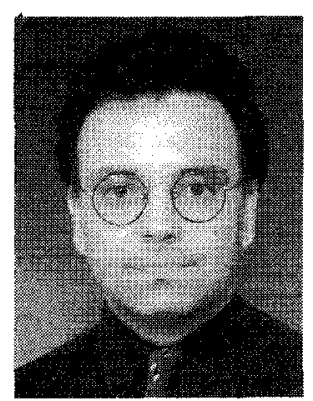

A. Can Özcan was born in Ankara, Turkey on October 29, 1965. He graduated from Middle East Technical University, Department of Industrial Design. While working as a professional designer and lecturer of design for stage design, ceramics, graphics and product design courses, he completed his Msc., and PhD. in Dokuz Eylül University and participated in the establishment of department of Industrial Design in İzmir Institute of Technology where he is working as an assistant professor.

His special interests include semiotics, design evolution, design methodology and CAD/CAM technologies. He has participated in a number of national and international congresses and exhibitions with provocative works regarding technology, design, and art, including environmental UN studies in Geneva. 